\title{
Vivir y morir según la ley. Reflexiones teóricas interdisciplinarias sobre la vida de la persona y el derecho a la vida
}

\section{To live and die according to law. Interdisciplinary theoretical thoughts on person's life and the right to life}

\section{PAULA SIVERINO BAVIO \& JARIS MUJICA*}

Resumen: El artículo aborda, desde la perspectiva de la antropología y la bioética jurídica, una serie de consideraciones sobre el derecho a la vida y la vida protegida por el derecho, partiendo de analizar las distinciones entre la vida del viviente y la vida de la persona, y reflexionando desde allí sobre los límites a la voluntad del sujeto enfermo que se encuentra en el tramo final de su existencia.

Palabras clave: vida de viviente - vida de la persona - medidas fútiles bioética - biopolítica

Summary: The article discusses different considerations on the right to life and life protected by law from an anthropologic and legal bioethics perspective based on the analysis made between «the living's life» and «the person's life» distinctions as well as thoughts about ill person's will restrictions at the final stage of his life.

Keywords: living's life - person's life - futile measures - bioethics - biopolitic

CONTENIDO: I. INTRODUCCIÓN.- II. LA VIDA-DEL-VIVIENTE-HUMANO ES DIFERENTE A LA VIDA-DE-LA-PERSONA.- III. MECANISMOS DE TUTELA Y DE CONTROL. ¿QUÉ VIDA PROTEGE EL DERECHO Y QUÉ PROTEGE EL DERECHO A LA VIDA?.- IV. LA PROTECCIÓN DE LA VIDA ANTE LA MUERTEY EL MORIR.V. CONSIDERACIONES FINALES.

\section{INTRODUCCIÓN}

La reciente sanción de la ley 26.529, la llamada «Ley de Muerte Digna», en Argentina, que contempla la posibilidad de tomar decisiones informadas sobre el final de la vida, incluyendo directivas anticipadas de rechazo a tratamiento médico, vuelve a poner en el escenario de la bioética jurídica los cuestionamientos sobre los alcances de la libertad individual frente a la proximidad de la muerte y el sufrimiento, las condiciones de humanidad o humanización que dan sentido a la vida 
de un sujeto y la regulación de las posibilidades de la ciencia sobre el cuerpo humano.

Las consideraciones sobre la vida, el objeto de protección del derecho a la vida y la vida protegida por el derecho son discusiones que subyacen al debate sobre las medidas fútiles y la admisibilidad del rechazo a tratamientos médicos en el proceso del final de la vida, dado que este es un espacio en donde se explicitan las visiones y tensiones sobre la vida como soporte de los derechos de la persona y la entidad del sujeto frente al derecho (en cuanto a la expresión de su identidad, autonomía y desarrollo de su personalidad).

Entendemos entonces que, antes de explorar la regulación sobre las conductas permitidas o prohibidas frente a la inmediatez de la muerte, es necesario estudiar las características del derecho a la vida y los conceptos de su formación. A su vez, el derecho a la vida requiere entender la formación del concepto «vida» y este es el objetivo de este artículo: se trata de presentar el debate en torno este concepto y sus orígenes teóricos. Esto es importante, pues la manera de construir el concepto genera tensiones sobre la consideración de «la vida» y su rol en la organización política y jurídica de la sociedad contemporánea impacta en las decisiones legales - normativas y/o jurisprudenciales - y estas, a su vez, en las decisiones sanitarias que van a afectar de manera directa al sujeto y a su entorno familiar en el trance final de la vida.

¿Cómo se considera a la vida desde la ley? En el Perú, el artículo 1 de la Constitución Política de 1993, establece que «La defensa de la persona humana y el respeto de su dignidad son el fin supremo de la sociedad y el Estado». El nuevo texto constitucional de 1993 cambia el artículo 1 que en la Constitución de 1979 señalaba: «La persona humana es el fin supremo de la sociedad y el Estado. Todos tienen obligación de respetarla y protegerla».

Aunque la modificación en el artículo 1 parezca un dato menor, ella, que se da luego del autogolpe de 1992 en una cuestionada reforma constitucional, legitima de alguna manera un cambio en el eje de acción del derecho, que de centrarse en «la persona humana» pasa a articularse en torno a «la defensa de la persona humana». Y esta «defensa» tendrá por objeto principal su «vida». Pero i) iquién es la «persona humana» objeto de protección?; ii) ¿qué vida defiende el derecho?; y iii) iqué protege el derecho a la vida? 


\section{LA VIDA DEL VIVIENTE HUMANO ES DIFERENTE A LA VIDA DE LA PERSONA}

Para abordar esta cuestión partiremos de una primera consideración: la persona no es producto de la reproducción sexual. La vida de la persona no es la misma que la vida biológica del viviente humano. Es más, para muchos sistemas culturales queda clara esta distinción y por ello no todos los vivientes humanos fueron considerados siempre personas: ser persona era un estatus que debía ganarse, pues se adquiría demostrando ciertos logros o atravesando complejos ritos de pasaje.

Persona, entonces, no es una categoría unitaria, no es una categoría de lo biológico, no es una categoría que venga de la naturaleza misma o de la profundidad última de la conciencia. Se trata, más bien, de una categoría cultural que en algunos casos se ha construido a través de los dispositivos de los sistemas teológicos, jurídicos o políticos. La persona, como la conocemos hoy, es una construcción tardía cuyo origen puede rastrearse en la historia reciente de Occidente, sobre todo en el siglo XX, en donde hubo un influjo particular para construir una idea común: a tal punto que en ese siglo la persona se convirtió en una categoría que parecía ser equivalente a ser humano viviente; y, por lo tanto, dicha apariencia llevó a la construcción de la ecuación en donde la vida del viviente humano implicaba por sí misma la vida de la persona.

En el contexto histórico del Occidente del siglo pasado, persona se convirtió en una categoría que se asentó como inmediata a la vida biológica. Así, esta asunción primera ha permitido que en el sentido común se presuma con facilidad que todos los vivientes humanos son personas por naturaleza predada, y que se trata de una constitución per se. Se reinventaron los derechos humanos, los derechos de las personas y el derecho a la vida como elemento vector ${ }^{1}$.

Persona es una categoría abierta que se ha construido de distintas formas y que atravesó —y atraviesa - diversas transformaciones. Hay hoy un debate que busca a la persona en la profundidad de las estructuras biológicas, lo que es ilustrado por dos de las cuestiones más discutidas en la actualidad: ¿cuál es el momento biológico en el que se inicia la vida de la persona?, y icuál es el momento biológico en el que cesa la vida de la persona? Y esto muestra el hilo de nuestro problema, pues la vida biológica del viviente humano no es la misma que la vida de la persona y, por lo tanto, encontrar el punto de inicio o de final de la vida de la persona en la vida biológica resulta una tarea imposible.
VIVIR Y MORIR SEGÚN LA LEY. REFLEXIONES TEÓRICAS

INTERDISCIPLINARIAS SOBRE LA VIDA DE LA PERSONA Y EL

DERECHO A

LA VIDA

TO LIVE AND DIE ACCORDING TO LAW.

INTERDISCIPLINARY

THEORETICAL

THOUGHTS ON

PERSON'S LIFE AND THE RIGHTTO LIFE 
En las sociedades occidentales contemporáneas han surgido también distintos enfoques sobre la persona y se han construido, además, discursos que determinan su existencia o marcan su situación en el aparato social. En la modernidad clásica ${ }^{2}$, estos aparatos estuvieron dispuestos, en gran medida, por la formalidad del discurso teológico cristiano y asentados en las codificaciones de los aparatos jurídicos formales. Aunque se asume, muchas veces, que es el derecho (y lo jurídico en general) quien tiene el monopolio de la categoría persona, resulta evidente, tras una revisión etnográfica, que esto no es así y que lo jurídico es uno, de varios campos, que ha construido definiciones de la persona y ha asumido una posición sobre la vida. Lo mismo sucede con las teologías. Incluso se puede indicar que los dispositivos jurídicos estuvieron muchas veces bajo la situación en que la teología hegemónica determinaba la constitución de los discursos y mandatos morales. Así, en Occidente, la Iglesia católica ha tenido un gran influjo sobre esta producción de discursos y ha tenido un peso importante en la construcción de la persona.

Nuestra noción de persona humana es fundamentalmente una noción cristiana:

[...] El paso de la noción de la persona, hombre revestido de un estado, a la noción de hombre sin más, a la de persona humana [...] se plantea como la de la unidad de la persona, la unidad de la iglesia y la unidad de Dios [...] Es a partir de la noción de uno cuando se crea la noción de persona, creo que en relación con las personas divinas, pero también y lo mismo, a propósito de la persona humana sustancia y forma, cuerpo y alma, conciencia y acto ${ }^{3}$.

Es interesante observar que, en las teologías clásicas, la vida de la persona no constituye un asunto biológico, sino un hecho espiritual; se trata de un espíritu encarnado en un cuerpo, un cuerpo sacralizado, desbiologizado. Durante siglos, para la teología dominante del cristianismo occidental quedó claro que las personas, los verdaderos vivientes humanos, eran aquellos que tenían espíritu. El «alma» que algunos seres humanos vivientes poseían determinaba su ser persona o su potencialidad. Así, se podía clasificar a los seres vivientes según si estos tenían alma o no (los «salvajes», los «indios», los «esclavos», los «bárbaros», los «negros», los «infieles», las «mujeres»). La persona radica, para estas miradas, en la espiritualidad y libertad que pautan el carácter moral de sus acciones ${ }^{4}$. La libertad del hombre revela su trascendencia vertical. Persona es entonces el «ser libre» y su libertad implica «responsabilidad, veracidad,

2 FOUCAULt, Michel. Las palabras y las cosas. Una arqueología de las ciencias humanas. Madrid: Siglo XXI, 1999.

3 MAUSS, Marcel. «Sobre una categoría del espíritu humano: la noción de persona y la noción del yo». En Sociología y antropología. Madrid: Tecnos, 1971, p. 329.

4 WoJTYLA, Karol. Persona y acción. Madrid: La Editorial Católica, 1982; FRANQUet, María José. Las claves de la antropología de Karol Wojtyla. Navarra: Ediciones Universidad de Navarra, 1996. 
autodeterminación y conciencia». Su trascendencia, basada en la espiritualidad, propicia el autogobierno del sujeto, a través del cual se revela Dios. Estos elementos que configuran la existencia (racionalidad, libertad, moralidad, espiritualidad) resultan categorías abstractas, diferentes de lo biológico. En estas primeras miradas podría decirse que, para estas teologías, la vida de la persona es también diferente de la vida del viviente biológico 5 .

Pero las cosas han cambiado y con el tiempo el espíritu ha tenido que penetrar las estructuras biológicas. En otras palabras, si bien la espiritualidad de la persona se revelaría en sus acciones, caracterizadas por ser morales ${ }^{6}$, se ha convenido que la unión celular del espermatozoide con el óvulo generaría una nueva persona, en tanto esta es considerada como una posibilidad espiritual, racional y trascendental, y se le ha otorgado al cigoto una personeidad (posibilidad o potencialidad de la persona en tanto realidad biológica y espiritual). ¿Qué significa esto? Pues se construye una mirada «teológica-biológica». Se suspende esa separación que parece una constatación evidente en las sociedades tradicionales donde la vida del viviente humano era diferente a la vida de la persona. Se asume la ecuación entre esas categorías, y al gestarla se ubica al espíritu en la «profundidad» de la biología, en el punto de partida de la vida del viviente humano. Ya no serían los signos exteriores de la cristiandad medieval los que permitirían identificar quiénes tienen alma y quiénes no y todo viviente humano sería per se una persona humana desde su existencia biológica?

La situación anterior ayuda a ejemplificar el problema: la biologización del debate sobre la vida, la construcción de una ecuación entre la vida del viviente humano y la vida de la persona. Y ocurrió que a mediados del siglo pasado, por primera vez, un supuesto hecho biológico determinaba la vida de una persona. Convertirse en persona se desritualiza. Los ritos que convertían, en las sociedades tradicionales, al sujeto en una persona, parecen suspenderse y se comienza a buscar el «origen» y su determinación en otros campos. ¿A qué se debió esta ecuación?, ¿a qué se debió el acercamiento entre lo biológico y lo teológico? Esto permite una segunda constatación: que no es una disposición trascendente, no es una disposición de principio la que gestó ese campo, y es más bien en relación con la política de la vida que gran parte de la Iglesia empieza su cercanía formal a los discursos de la ciencia médica y de la biología.

Esto es ilustrado claramente por dos debates muy álgidos que tienen lugar desde los años setenta, cuando se puso a punto la tecnología que permitirá observar y controlar el proceso reproductivo fuera 
del cuerpo humano, i) la fecundación in vitro - lo cual llevó a un fuerte cuestionamiento sobre las obligaciones morales frente a un ser vivo en etapas iniciales de su desarrollo-; y ii) las técnicas de trasplantes de órganos, que obligaron a replantear el concepto jurídico y social de muerte, así como las obligaciones morales frente a personas con pérdida total e irreversible de sus facultades cerebrales superiores $y / o$ vegetativas. El éxito de estas tecnologías y de aquellas que vendrían después visibilizarán los extremos de «ingreso y salida» a las realidades llamadas «ser humano» $\mathrm{y}$ «persona» $\mathrm{y}$ la necesidad, esgrimida por diversos actores sociales, de regular y controlar estos procesos.

Por otro lado, los descubrimientos y avances en relación con el genoma humano trajeron consigo la posibilidad de que el hombre se modifique a sí mismo como especie y una enorme expectativa sobre las posibilidades - percibidas como ilimitadas - terapéuticas, comerciales, etcétera, «encerradas» en el código del ADN. El genoma se transformó, en las últimas décadas, en un elemento de compleja percepción social, deviniendo, entre otras cosas, en el depositario último de las verdades «esenciales». Se busca en la expresión de los genes la explicación no solo de las enfermedades, sino de rasgos personales, conductas, tendencias, limitaciones. Microscopio mediante, la identidad del sujeto parece estar escrita en su genoma, a la espera de ser develada. Y el genoma no solo determinaría personalidades, sino que, merced los dispositivos legales, será el elemento creador de «personas». «Persona» es, para la ley, todo ser humano y un ser humano sería aquel que posee genoma humano.

Esto muestra de antemano un problema que se arrastra en las diferentes posturas, a saber, la pretensión de definir a la persona desde la prueba biológica y los indicadores biomédicos. Desde las alas más conservadoras hasta las más progresistas, la confusión entre la vida de la persona y la vida biológica de prueba científica resulta un asunto extendido. Por confusión, descuido o aseveración de principios estos términos aparecen en muchos casos indistintamente. La vida de la persona y la vida biologizada del viviente humano parecen ahora constituir una unidad. Esta ecuación, la unificación de las vidas, implica un aparato de organización conceptual que ha sido aceptado incluso por las formas de los pactos institucionales, las formas políticas y las estructuras jurídicas y de derechos. Hay cierta unidad formal entre la vida del viviente humano y la vida de la persona.

El artículo 6 del Pacto Político afirma: «El derecho a la vida es inherente a la persona la persona humana. Este derecho estará protegido por la ley. Nadie podrá ser privado de la vida arbitrariamente $[\ldots] \otimes^{8}$. Con esta afirmación, que marca la estructura de la ecuación, se construye la

8 COOK, Rebeca; Bernand DiCKENS \& Mahmoud FATHALLA. Salud reproductiva y derechos humanos. Integración de la medicina, la ética y el derecho. Bogotá: Profamilia, 2003, pp. 154-155. 
relación indefectible de la modernidad tardía: la vida del viviente, la vida de la persona, la vida biológica y la vida jurídicamente dispuesta se unifican. De tal modo, el sentido biológico que se le otorga al inicio de la vida humana nace en la categoría vida de las estipulaciones normativas. En efecto, estas se basan en el reconocimiento de las etapas de desarrollo embrionario para determinar el momento en que se es sujeto de derechos ${ }^{9}$, le demandan a la ciencia el deber formal de marcar indicadores objetivos que determinarían biológicamente al viviente y biológicamente a la persona. Y así, la normativa del derecho y sus brazos exteriores regulan en codificaciones las acciones y los datos que la biología y las ciencias médicas llevan a cabo en el experimento científico. La producción jurídica y el saber de la biología se unen y construyen principios morales que operarían como principio de causa y acción ${ }^{10}$. El gran saber de la biología prima como principio de organización de datos, pero no puede ser regulado sin un aparato que lo formalice en el reglamento y que, al mismo tiempo, le otorgue su límite de acción posible (el Estado, la política, la ley) y su brazo exterior disciplinario (el derecho).

Las teologías también ingresan al debate y adoptan una posición tratando de ubicar al espíritu en los fenómenos biológicos y ubicándose así en el discurso político. En lugar de oponerse a la existencia del discurso científico (como había sucedido en toda la Edad Media y gran parte de la modernidad), en la modernidad tardía las teologías deben construir un discurso conciliador y al mismo tiempo colonizador de una parte de la narrativa de la ciencia. Lo mismo sucede con el derecho y las disciplinas jurídicas. La ciencia entonces no resulta aséptica, sino que se dispone atrapada entre los dos grandes discursos de la modernidad temprana, a saber, la teología y el derecho.

Esto es ilustrado de manera muy clara por la discusión sobre el estatuto ontológico del embrión ${ }^{11}$. Las posiciones en torno a la consideración ontológica y jurídica de las etapas iniciales del desarrollo de un embrión humano toman, en unas y otras posturas, el criterio biológico como eje decisivo para determinar la pertenencia a la comunidad humana, así como la consiguiente protección debida por el ordenamiento jurídico.

9 RuBIO, Marcial. El ser humano como persona natural. Biblioteca para leer el Código Civil, Vol. XII. Lima: Fondo Editorial de la Pontificia Universidad Católica del Perú, 1992; GonZALES MANTILLA, Gorki. La consideración jurídica del embrión in vitro. Lima: Fondo Editorial de la Pontificia Universidad Católica del Perú, 1996; Fernández Sessarego, Carlos. «El concebido en la doctrina y en la legislación peruana del siglo XX». En Bioética y biojurídica, la unidad de la vida. Lima: Ediciones Jurídicas Unife, 2002, pp. 37-70; EsPINOZA, Juan. Derecho de las personas. Lima: Gaceta Jurídica, 2004; PARRA, Ivonne. «Consideraciones biojurídicas sobre la vida en el embrión humano». Dikayosine. Revista de Filosofía Práctica, IX, 16 (2006), pp. 35-53.

10 PotTeR, Van Rensselaer. «Bioethics: The science of survival». Perspectives in Biology and Medicine, 14, 1 (1970), pp. 127-153.

11 FIGUEROA YÁÑEZ, Gonzalo. «El comienzo de la vida humana. El embrión como persona y como sujeto de derecho". En BERGEL, Salvador \& Nelly MINYERSKY (coord.). Bioética y Derecho. Sante Fé: Rubinzal Culzoni, 2003, pp. 283-311, p. 284. 
Coinciden en esto la tesis de la fecundación (unión del óvulo y el espermatozoide y unión de los pronúcleos), la de la anidación, la del surco neural y estructuras del sistema nervioso, con sus variantes.

Si bien, a medida que se alejan del momento de la fecundación, las teorías buscan signos característicos de humanidad, toman para ello como punto de partida determinantes biológicos. De hecho, podría decirse que la tesis de la anidación y de la fecundación descansan exclusivamente en elementos de carácter fisiológico: en el caso de la anidación, el superar el estadio de totipotencia así como el mayor índice de pérdida en caso fuera un proceso fallido y, fundamentalmente, el contar con un medio apropiado e imprescindible para permitir la continuación del desarrollo mediante la interacción con la mujer (lo que no sucede en el caso de los embriones extra-uterinos).

Es interesante el razonamiento en la tesis de la fecundación o singamia ${ }^{12}$, donde el carácter de humano y, por ende de sujeto de derecho, será atribuido exclusivamente en función de la presencia de ADN humano, independientemente de lo inexacta que puede resultar esta aseveración aun desde el punto de vista científico y de las escasas posibilidades fácticas de que un proceso de fecundación culmine en un nacimiento ${ }^{13}$.

La defensa de la tesis del surco neural o rudimentos del sistema nervioso, en el debate que tuvo lugar con motivo del pedidode inconstitucionalidad de la reforma del Código Penal de México D.F. ${ }^{14}$, grafica lo que se viene sosteniendo. La reforma consistió en que se consideraría «aborto» a la interrupción del embarazo a partir de la duodécima semana, sosteniendo como motivo principal para permitir la libre interrupción del embarazo en el primer trimestre que, al no estar desarrolladas las estructuras del sistema nervioso central que caracterizarían al ser humano como persona humana, el embrión debía ser protegido como bien jurídico valioso (la vida humana en formación), pero no como sujeto de derecho, no siendo reconocido como titular de deberes y derechos y cediendo por ende su vida ante los derechos de la mujer que decidiera interrumpir el embarazo en esta etapa:

Debe tenerse presente que la vida y vida humana son conceptos y realidades diversos. Poseen vida los animales, las plantas, las bacterias, los óvulos y los espermatozoides, y desde luego, los seres humanos, pero vida humana la tienen solo estos últimos [...] El embrión no tiene

12 MARTíneZ, Stella Maris. «El estatuto ontológico del embrión». En GaraY, Oscar (coord.). Responsabilidad profesional de los médicos. Ética, Bioética y Jurídica, Civil y Penal. Buenos Aires: La Ley, 2002.

13 SIVERINO BAVIO, Paula. «Impugnación de la maternidad, identidad y reproducción asistida heteróloga en el Perú: cuando los genes ganan y las personas pierden". Derecho de Familia. Revista Interdisciplinaria de Doctrina y Jurisprudencia, 55. Buenos Aires: Abeledo Perrot, 2012, p. 207; Gracia, Diego. Ética de los confines de la vida. Bogotá: El Búho, 1998.

14 Corte Suprema de Justicia mexicana, 2007, acción de inconstitucionalidad 146/2007 y su acumulada $147 / 2007$. 
las condiciones que particularizan al ser humano, en virtud de que carece de las estructuras, las conexiones y las funciones nerviosas necesarias para ello y desde luego es incapaz de sufrir o gozar. Biológicamente no puede considerarse un ser humano ${ }^{15}$.

VIVIR Y MORIR

SEGÚN LA LEY.

¿Qué es lo importante de las referencias anteriores? Pues no se trata de tomar posición en debates específicos, sino de entender la importancia del contenido teórico de estas tensiones: en el fondo hay una batalla por determinar «el punto de inicio de la vida de la persona» y para determinarla se recurre a indicadores biológicos. La vida humana biologizada se busca en la unión de los gametos, en la anidación del cigoto o en la formación del embrión. El microscopio nos transporta a las profundidades de las estructuras físicas, a los cuerpos celulares que componen tejidos, pero ahí no radica la vida de las personas, sino solo la organización molecular de la vida de los vivientes y sus cuerpos. Vale la pena observar entonces cómo el derecho construye sus discursos sobre la vida. Y cómo en este devenir se enfrentarán, en el mismo campo de lo jurídico, aquellos dispositivos construidos sobre la vida del viviente y su soporte biológico, y la vida de la persona, reconocida en su libertad y su proyecto de vida.

REFLEXIONES

TEÓRICAS

INTERDISCIPLI-

NARIAS SOBRE

LA VIDA DE LA

PERSONA YEL

DERECHO A

LA VIDA

TO LIVE AND DIE

ACCORDING TO

LAW.

INTERDISCIPLINARY

THEORETICAL

THOUGHTS ON

PERSON'S LIFE AND

THE RIGHT TO LIFE

\section{MECANISMOS DE TUTELA Y DE CONTROL: ¿QUÉ VIDA PROTEGE EL DERECHO Y QUÉ PROTEGE EL DERECHO A LA VIDA?}

El derecho no es un dispositivo aséptico, se trata de un campo cambiante y en cuya maquinaria se van escenificando las tensiones sociales. El concepto de persona en este terreno no escapa a estas tensiones y, por supuesto, que esté dispuesto en la maquinaria jurídica no quiere decir que esté separado de los debates de la teología, la ciencia formal, de la biología o de los valores sociales y de los dispositivos de poder.

Mientras que algunos han entendido que el derecho a la vida protege no solo el reconocimiento biológico, sino el tener condiciones dignas de existencia ${ }^{16}$, buena parte de la doctrina ha entendido que el derecho a la vida protege la existencia ${ }^{17}$; o bien, que aun reconociendo que el derecho a la vida puede tutelar una realidad más compleja — corporeidad, psiquisimo y ser libertad del hombre - ${ }^{18}$, la preservación de la existencia biológica, en cuanto sustrato material, es fundamental para definir

15 CARPIZO, Jorge \& Diego VALADÉs. Derechos humanos, aborto y eutanasia. México D.F.: Universidad Nacional Autónoma de México, 2008, pp. 4-5; las cursivas son nuestras.

16 ESPINOZA, Juan. Derecho de las personas. Quinta edición. Lima: Rhodas, 2006, p. 195.

17 CIFUENTES, Santos. Derechos personalísimos. Segunda edición. Buenos Aires: Astrea, 1995; ToBíAs, José. Derecho de las personas. Instituciones de Derecho Civil: parte general. Buenos Aires: La Ley, 2009; VILA-CORO, María Dolores. Introducción a la biojurídica. Madrid: Universidad Complutense de Madrid, 1995.

18 Fernández Sessarego, Carlos. Los 25 años del Código Civil Peruano de 1984. Lima: Motivensa, 2009, p. 319. 
por ejemplo, sus límites, su carácter de indisponible y la consolidación de sus derechos. Y esta existencia concreta será comprendida como subsistencia biológica, en la medida en que solo un ser humano vivo puede ser titular de deberes y derechos. «Varios derechos derivan del ser biológico viviente humano. Resguardan la materia natural del hombre, el componente infaltable del tránsito terrestre» ${ }^{19}$.

Una sentencia paradigmática donde ello se expresa con claridad es la sentencia del presente en el expediente número 02005-2009 PA/TC «ONG Acción de Lucha Anticorrupción» de noviembre de 2009 del Tribunal Constitucional peruano:

[...] [la dignidad] supone la vigencia irrestricta del derecho a la vida y constituye su proyección, es el de mayor connotación y el presupuesto ontológico para el goce de los demás derechos, ya que el ejercicio de cualquier derecho, deviene inútil ante la inexistencia de vida física de un titular al cual puedan serle reconocidos tales derechos ${ }^{20}$.

Esta sentencia es particularmente interesante, ya que el punto central de la demanda consistía en determinar a qué entidad biológica, en qué momento del desarrollo embrionario de un nuevo ser vivo humano, se le atribuiría a este el carácter de sujeto de derecho. La cuestión requerirá, para los jueces, esclarecer el contenido del artículo 1 del Código Civil, el cual enuncia: «La persona humana es sujeto de derecho desde su nacimiento. La vida humana comienza con la concepción. El concebido es sujeto de derecho para todo cuanto le favorece. La atribución de derechos patrimoniales está condicionada a que nazca vivo» ${ }^{21}$.

Aquí el ordenamiento peruano introduce una relación de género a especie entre los distintos tipos de sujetos de derecho. Así, en cuanto al ser humano individualmente considerado, se llamará «persona» al ser humano ya nacido y «concebido» al ser humano antes del nacimiento. Resulta clave establecer cuál será el punto de partida de su condición legal, y para ello la referencia es biológica: «concebido» será el producto de la concepción. Y los jueces se responderán que la concepción se identifica con la unión del óvulo con el espermatozoide (teoría de la fecundación), por ende, aquella célula surgida de la fusión de los gametos sexuales será un nuevo ser humano (un viviente humano) y un nuevo sujeto de derecho (la vida de una persona), idéntico en su entidad y reconocimiento legal a un niño o un adulto.

Pero es además curiosa la mención al inicio de la vida. El Código Civil dice «la vida humana comienza con la concepción». Ello llevará a los jueces a preguntarse, como una cuestión central, cuándo inicia la vida. 
Como si esta fuera una pregunta a ser respondida por el derecho o la biología. La vida es un proceso que se transmite, sin embargo, el Tribunal entiende que es fundamental entender cuándo empezaría la vida, pese a no remitirse para ello a las teorías sobre el origen del universo y la materia orgánica. Luego dirá que interesa ver cuándo inicia la vida de un nuevo ser humano, y fijará este momento en el inicio del proceso de fecundación, por entender que la configuración del genoma es suficiente para otorgar a esta entidad la condición de sujeto de derecho, dotado de dignidad y derechos. La personalidad jurídica iniciará entonces antes que sea posible saber si el proceso embriológico no resultó fallido; antes de poder determinar si se trata de un solo sujeto o más, en caso fueran gemelos; antes de que esta entidad «humana» tenga un cuerpo o siquiera un rudimento corpóreo. La atribución de deberes y derechos, entre ellos la inviolabilidad de la vida, quedará garantizada con la aparición del código genético, que será tomado como punto de partida en la medida en que este código marcaría el inicio de un nuevo ser vivo ${ }^{22}$.

Esto es dicho claramente por el juez de primera instancia, quien apoya la misma tesis por ser «la que asume la defensa de la vida desde el momento de la fecundación». Vida biológica que antecede incluso al ser viviente, que, aunque ya investido de su calidad de sujeto de derecho, tiene un altísimo porcentaje de probabilidades de no lograr avanzar en su desarrollo.

El derecho a la vida así entendido protegería entonces la promesa, el halo vital de la existencia biológica, y ello llega al extremo de proteger una vida desprovista de un cuerpo y una biografía, pero investida de personalidad jurídica, donde el rasgo de humanidad descansa en el código genético (compartido, e indiferenciado en esta etapa, con la placenta, el cordón umbilical, etcétera), al cual se le atribuye un alto carácter simbólico.

Esta tesis, sostenida por el Tribunal, va incluso más allá de la existencia misma de la vida biológica situada en un viviente, retrocediendo hasta la mera promesa o expectativa de esta vida. Ello se ve en las sentencias que, al abordar la cuestión de los embriones congelados, determinan la calidad de sujetos de derechos de los mismos, de modo tal que esta potencial vida biológica, que aún no ha tenido la ocasión de devenir ni biológicamente viable (una vida situada en ser viviente), ni mucho menos, vida biográfica, será considerada incluso «superior» a los derechos de otros sujetos, en el caso, los de sus progenitores genéticos, en más de una sentencia sobre fecundación in vitro.

Así, en el Perú en el año 2009, una jueza de primera instancia conminó a una pareja que había tenido una hija por un proceso in vitro con 
maternidad subrogada a que, por sí o por terceros, gestaran los tres embriones congelados producto de esta in vitro, ya que tenían la obligación de «hacer efectivo su derecho a la vida», bajo apercibimiento de sancionarlos, declararlos en abandono y darlos en adopción ${ }^{23}$.

En un similar orden de ideas, en la Argentina, en el año 2011, se le reconoció a una mujer que estaba divorciándose el derecho, en su calidad de madre de los embriones congelados, de poder transferirlos a su vientre para intentar quedar embarazada, en contra del reclamo de su ex esposo que solicitaba su destrucción por negarse a devenir nuevamente padre cuando había ya finalizado su relación (su proyecto) marital:

Se impone, una interpretación del elemento gramatical — humanista y finalista - acorde con la evolución de los avances científicos y congruente con el pensamiento del codificador de tutela de la vida humana (arg. arts. 63, 70, 72, 75 Cód. Civil), superadora de una antinomia manifiestamente discriminatoria que diferenciara la situación del concebido según el diverso lugar en que se produce el contacto fertilizante de las células germinales $[\ldots]$

Puede contestarse con la elemental consideración que el concepto de «persona humana» equivale a la de «ser humano», cuyo proceso existencial abierto comienza, no con el nacimiento sino con la concepción, terminando con la muerte [...]

Ello involucra al concebido «in vitro» en virtud de su sustantividad humana que la biología le reconoce desde el momento en que se produce la concepción, idéntica a la del concebido en el seno materno.

La frase del penúltimo pasaje de la cita es fundamental: «el concepto de persona humana equivale a la de ser humano», pues esa es la ecuación que es necesario poner en discusión y el centro de este artículo. Así, esta forma de entender la «vida» eje de protección del sistema jurídico aparece como una vida biologizada, naturalizada, anclada al ADN, depositario último de saberes, expectativas y certezas. Sostener que el derecho a la vida protege la existencia, sobre todo si esta existencia es meramente biológica, lleva a una concepción casi parasitaria del individuo que debe sostener este valor biológico superior a sí mismo, a su biografía, su identidad, su humanidad misma, en razón de que es el antecedente material que lo soporta, desconociendo las condiciones de humanidad que le dan sentido a esta existencia, que no solo es biología sino fundamentalmente biografía.

Y es justamente este el punto de la discusión, pues el debate sobre la vida y el viviente, no resulta un elemento de descubrimientos trascendentes,

23 Caso C.M.S.E. c/ J.L.A. de O. y otro s/ impugnación de la maternidad. Décimo quinto juzgado de familia de Lima, 2009. 
sino, más bien, el reconocimiento de acuerdos políticos y negociaciones sobre estos conceptos. Existe un ideario social, una necesidad latente y compartida de buscar en la ley certezas, cuando lo que cabe esperar de ella, por su misma finalidad y carácter, son solamente acuerdos.

\section{LA PROTECCIÓN DE LA VIDA ANTE LA MUERTE Y EL MORIR}

Si se tomara como cierto que la «vida» que protege el derecho es la existencia biológica (la vida del viviente), iqué sucede entonces con la consideración del proceso de morir y de la muerte? Legalmente se considera a la muerte un «hecho natural con efectos jurídicos», donde la referencia a «lo natural» evoca nuevamente este anclaje biológico que pretende desconocer que:

[La] muerte no es ni ha sido nunca un hecho «natural» simple y unívoco, sino un complejísimo fenómeno «cultural»; es una creación del hombre. Esto se advierte muy bien al formular una pregunta tan simple como la de cuándo esta muerto un ser humano. La única respuesta indudable es que el hombre está muerto cuando el cuerpo se descompone. La corrupción orgánica es el único signo cierto de muerte. Ahora bien, este hecho biológico nunca ha sido culturalmente asumible ${ }^{24}$.

Prueba de ello es que en la mayoría de los ordenamientos jurídicos, descartada la figura de la muerte civil, conviven al menos tres definiciones de muerte: la muerte cardiopulmonar, la muerte encefálica o cerebral y la muerte presunta. En el caso peruano, las dos primeras se encuentran en la ley de trasplantes de órganos: «Se considera muerte para este Reglamento el cese irreversible de la función encefálica o la función cardiorespiratoria de acuerdo a los protocolos que se presenten en este Reglamento $[\ldots] »^{25}$. «Se considera muerte encefálica al cese irreversible de las funciones del tronco encefálico cuyo protocolo de diagnóstico se establece en los artículos 7 y $8[\ldots] »^{26}$.

Estas disposiciones son compartidas por la mayoría de los ordenamientos jurídicos. Sin embargo, y en relación con la constatación de la muerte, debe tenerse en cuenta que:

Desde el punto de vista conceptual la determinación de la muerte no es una constatación empírica desarrollada incluso con el auxilio de medios técnicos sofisticados. Ni siquiera se trata de un juicio de valor. Más precisamente la verificación de la muerte es una deducción teórica a partir de unos hechos. La confirmación de la muerte se coloca, 
por lo tanto, en un nivel metaempírico, que es el de la interpretación de los hechos ${ }^{27}$.

La muerte marca, para el derecho, el fin de la persona, pero para poder establecer el ámbito de potestades del sujeto que se encuentra en el tránsito final de su vida biológica, debe además contemplarse lo que prevé la norma en cuanto a los márgenes de disposición del propio cuerpo, así como las pautas sobre la disponibilidad o no del derecho a la vida y a la integridad. A este respecto el Código Civil peruano señala:

El derecho a la vida, a la integridad física, a la libertad, al honor y demás inherentes a la persona humana son irrenunciables y no pueden ser objeto de cesión. Su ejercicio no puede sufrir limitación voluntaria, salvo lo dispuesto en el artículo $6^{28}$.

Los actos de disposición del propio cuerpo están prohibidos cuando ocasionen una disminución permanente de la integridad física o cuando de alguna manera sean contrarios al orden público o a las buenas costumbres. Empero, son validos si su exigencia corresponde a un estado de necesidad, de orden médico o quirúrgico o si están inspirados por motivos humanitarios ${ }^{29}$.

El escenario para reflexionar sobre el valor de la voluntad del enfermo y la procedencia o no de ciertos tratamientos médicos en el final de la vida será demarcado entonces por el principio de la irrenunciabilidad o indisponibilidad de la vida y la integridad, el principio de necesidad terapéutica y el contenido del derecho a la vida. Cómo se evaluarán aquellas conductas relacionadas con las llamadas «medidas fútiles», la limitación del esfuerzo terapéutico en personas conscientes o inconscientes, las directivas anticipadas de tratamiento médico y la eutanasia, dependerá, en buena medida, de aquello que se considere que protege el derecho a la vida: si la vida biológica, o bien una vida, que sin negar su sustento material biológico, es fundamentalmente, en cuanto vida de la persona, vida biográfica. La misma cuestión de la irrenunciabilidad del derecho a la vida y su limitación voluntaria está sujeta a esta discusión.

Así, por ejemplo, hay una marcada distinción entre aquellos que consideran que el suspender tratamientos de soporte vital en un sujeto que lleva varios años en estado vegetativo persistente es «eutanasia pasiva» — para algunos regulable legalmente, para otros prohibida $-{ }^{30} \mathrm{y}$ quienes ven en esta conducta un ejercicio del derecho a la integridad: 
la limitación del esfuerzo terapéutico ${ }^{31}$. Lo mismo podría decirse del no iniciar medidas consideradas fútiles, como pueden ser medidas se soporte vital, maniobras de reanimación u otros tratamientos, en pacientes que no van a experimentar ninguna mejoría en caso de ser sometidos a estas medidas o tratamientos, sino que, por el contrario, van a ver mermada la calidad de su tiempo de vida y su dignidad. Algo similar ocurre con el reconocimiento legal de las directivas anticipadas de tratamiento médico, también llamadas living will, o declaraciones vitales de voluntad ${ }^{32}$.

La renuencia, o el abierto rechazo, de numerosos ordenamientos jurídicos como es el caso del Perú, a aceptar estos documentos, en los que queda expresada la voluntad del sujeto de no aceptar tratamientos desproporcionados o extraordinarios conforme las circunstancias, y/o nombrar un representante para tomar las decisiones médicas que hiciera falta en caso de perder el discernimiento, expresa la dificultad, tanto del sistema sanitario cuanto del jurídico, de aceptar que el proyecto vital de un sujeto puede llegar hasta la disposición misma de las condiciones de su proceso de muerte.

Desde lo jurídico se sostiene que estas disposiciones serían inválidas, al menos hasta no ser puntualmente reguladas por una vía legislativa expresa, porque el sujeto carecería de la posibilidad de decidir sobre el «adelantamiento» de la propia muerte; sobre todo si se encuentra inconsciente y esta decisión es subrogada. Desde el espacio sanitario, para muchos profesionales de la salud, formados aún en un modelo mecanicista y que consideran ya no a la enfermedad, sino a la misma muerte, un enemigo a vencer, la vida debe preservarse ante todo, aún en contra de la voluntad del paciente. Como advierte Gracia: «La tesis médica clásica ha sido que el médico no debe nunca abandonar a su paciente y que por lo tanto, debe seguir intentándolo todo mientras quede el más mínimo resquicio de vida. "Mientras hay vida hay esperanza", dice el refrán castellano, por lo tanto ninguna intervención puede considerarse en principio fútil o inútil» ${ }^{33}$.

Siendo la visión generalizada en el Perú que el derecho a la vida protege la vida biológica, y que tanto la vida como la integridad corporal son indisponibles, existe una tendencia a la incertidumbre de los profesionales de la salud en los procesos de toma de decisiones al final de la vida de sus pacientes. Y se han verificado situaciones problemáticas, sea porque las decisiones de limitar el tratamiento se adoptan sin ser consultadas con

31 BLANCO, Luis Guillermo. «Homicidio piadoso consentido». En TEALDI, Juan Carlos (dir.). Diccionario Latinoamericano de Bioética. Bogotá: Unesco/Red Latinoamericana y del Caribe de Bioética/ Universidad Nacional de Colombia, 2008, pp. 503-506, p. 504; GRACIA, Diego. Ob. cit., p. 266.

32 Rabinovich Berkman, Ricardo. Actos jurídicos y documentos biomédicos. Buenos Aires: La Ley, 2004 , p. 339.

33 Gracla, Diego. Ob. cit., p. 257.

VIVIR Y MORIR

SEGÚN LA LEY.

REFLEXIONES

TEÓRICAS

INTERDISCIPLI-

NARIAS SOBRE

LA VIDA DE LA

PERSONA Y EL

DERECHO A

LA VIDA

TO LIVE AND DIE

ACCORDING TO

LAW.

INTERDISCIPLINARY

THEORETICAL

THOUGHTS ON

PERSON'S LIFE AND

THE RIGHT TO LIFE 
la familia o el enfermo por entender que se estaría realizando una acción irregular (lo cual es ilícito); o bien, que aun cuando el enfermo y/o la familia soliciten el no adoptar medidas fútiles — lo que amén de ser un ejercicio regular de la profesión es un comportamiento contemplado en el Código de Ética Médica- los médicos las aplican o no las suspendan por entender, erróneamente, que hacerlo sería una conducta eutanásica. Otra situación se da cuando el enfermo solicita no iniciar o suspender medidas fútiles, y algún miembro de la familia se opone. Allí, el médico no considera la decisión del paciente por temor a ser demandado y procesado civil y penalmente por los familiares luego del deceso del paciente.

Para la ley, la muerte es un hecho que pone fin a la persona como sujeto de derechos, por lo tanto, el permitir, adelantar o propiciar la muerte implica no solo la extinción de un ser viviente, sino la de un sujeto de derecho. Y es allí donde la supervivencia de la «personalidad jurídica» pareciera enfrentarse al ser humano que la aloja, en la encrucijada de un cuerpo sufriente, un cuerpo que será interdicto, sustraído al individuo por la ley, en aras de su protección. Al ubicar a la persona en un cuerpo biológico y al construir derechos de defensa de la vida biológica universal es que los derechos quedan imbricados a la biología y al cuerpo como entidades de control, supervisión y tutela.

En definitiva, en esta visión prima la defensa de una vida biológica anclada a un cuerpo que la sostiene, pero que en el cuerpo sufriente, agonizante, lo trasciende reclamando ser protegida aun a instancias de la persona que la aloja sin poder tomar decisión sobre ella y a la cual solo le cabe esperar la llegada de la muerte «natural». Ello considerando además la paradoja de que nada hay de «natural» en la muerte intervenida.

Desde el extremo contrario a esta posición, partiendo de la noción biográfica, identitaria, del sujeto, que experimentará como punto culminante de su vida la propia muerte, se admite que en una sociedad democrática se debe reconocer un margen de decisión al individuo que tarde o temprano enfrentará el tránsito hacia la muerte. En ese sentido se ha sostenido que:

[...] el proceso de morir, la tanasía —que no es el tánatos, la muerte, como muchos equivocadamente creen, y constituye algo muy distinto-, es un segmento con identidad propia, irrepetible por definición, dentro de la existencia. Las declaraciones vitales de voluntad apuntan a incorporarlo jurídicamente dentro del proyecto de autoconstrucción del sujeto, permitiéndolo controlar su suerte, dentro de la medida en que a los humanos nos es deferida, hasta los momentos postreros ${ }^{34}$. 
¿Qué maneras de ver la vida se disponen tras estos debates? Para unos la vida es la vida digna (la vida de la persona), para otros esta vida está constreñida a un cuerpo biológico que obedece al control de instancias supremas al propio sujeto (la vida del viviente biológico). El debate de fondo es la consideración sobre la relación entre la vida de la persona y la vida del viviente y la manera en la que la estructura del segundo dispone la posibilidad de autonomía del primero.

\section{CONSIDERACIONES FINALES}

Primero. Hay una diferencia clara entre la vida de la persona y la vida biológica del viviente humano. Es evidencia de ello que la construcción de la ecuación entre estos dos elementos ha sido relativamente reciente (mediados del siglo XX) y que ha anclado la construcción de la vida de la persona, como construcción de derechos, a los dispositivos biológicos e indicadores biomédicos. Esta ecuación ha generado que se busque en los indicadores biomédicos los orígenes de la vida de la persona y que, en algunos casos, los derechos del sujeto que decide estén anudados al movimiento celular de los cuerpos.

Segundo. Los debates bioéticos sobre diversos temas (entre ellos la fecundación in vitro, el asunto de la interrupción del embarazo, la ovodonación, la eutanasia) aparecen dentro de la construcción de la ecuación indicada. La vida de la persona de derechos aparece constreñida por la vida del viviente biológico que es regulado por los dispositivos formales del derecho y por el discurso de la naturaleza. ¿Qué es lo importante de esto?, que la regulación sobre estas definiciones no está marcada por dispositivos que emanan de la naturaleza, sino por los conceptos en construcción y las fuerzas políticas (biopolítica) que las producen. Es entonces importante entender que no se trata de buscar certezas en las disposiciones del derecho, sino acuerdos y arreglos institucionales sobre conceptos coyunturales.

Tercero. El derecho a la vida aparece como un eje fundamental de la construcción de los derechos humanos. En efecto, como su centro de ordenamiento. Sin embargo, el derecho a la vida de la persona y el derecho a la vida del viviente aparecen en colisión constante en los asuntos bioéticos. ¿Cómo determinar la superioridad de uno? ¿Cuáles son los puntos límites de esta colisión? Lo importante es entender que la construcción de este derecho aparece con una tensión de origen y, por lo tanto, con acuerdos institucionales que aún están en proceso de negociación y construcción. 